\title{
Body Mass Index-Dependent Ventilatory Parameters From Respiratory Inductive Plethysmography During 6-Minute Walk Test
}

\author{
Yann Retory MSc, Carole de Picciotto MD, Pauline Niedzialkowski MSc, \\ Michel Petitjean MD PhD, and Marcel Bonay MD PhD
}

\begin{abstract}
BACKGROUND: Walking is part of obesity management. Assessment of ventilatory impairments and consequences for gait induced by obesity could be clinically helpful. We aimed to develop a method to accurately monitor ventilation with respiratory inductive plethysmography (RIP) in subjects with high body mass indices (BMIs) during a 6-min walk test (6MWT). METHODS: 25 volunteers were divided into 2 groups based on BMI $\left(<25\right.$ or $\left.>30 \mathrm{~kg} / \mathrm{m}^{2}\right)$ and performed a $6 \mathrm{MWT}$ with a calibrated RIP. Ventilatory parameters (tidal volume $\left[\mathrm{V}_{\mathrm{T}}\right]$, inspiratory $\left[\mathrm{T}_{\mathrm{I}}\right]$ and expiratory $\left[T_{E}\right]$ times, $V_{T} / T_{I}$ ratio, and $T_{I} / T_{\text {tot }}$ ratio) were determined after processing RIP signals with a custom-made algorithm designed to discriminate tissue motion artifacts and respiratory cycles in the time domain. Six-min walk distance and average speed by minute were collected. RESULTS: The number of artifacts removed by the algorithm used for artifact removal was higher for high-BMI subjects and was correlated to their individual values $(\mathrm{r}=0.66, P<.001)$. Six-min walk distance was lower for the group with a higher BMI $(P=.001)$. ANOVA revealed effects of exercise for $V_{T}, T_{I}$, and $T_{E}(P<.001)$ and also BMI effects in the course of the $6 \mathrm{MWT}$ for $V_{T}, T_{I}, T_{E}, V_{T} / T_{I}$, and $\mathrm{T}_{\mathrm{I}} / \mathrm{T}_{\text {tot }}(P<.001$ for each of them). CONCLUSIONS: This respiratory monitoring method is sufficiently sensitive to point out differences between rest and exercise as well as locomotor and ventilatory differences relative to BMI during the 6MWT. Thus, this system gives useful information from the 6MWT for clinicians who want to assess respiratory patterns of patients during this commonly used test. Key words: respiratory inductive plethysmography; 6-min walk test; tidal ventilation; body mass index; artifacts; submaximal exercise. [Respir Care 2016;61(4):521-528. () 2016 Daedalus Enterprises]
\end{abstract}

\section{Introduction}

There has been an increase in the number of overweight people in the general population of western countries. Body mass index (BMI), defined as the ratio of the body weight expressed in mass units $(\mathrm{kg})$ over the square of body height in meters, is a widely accepted indicator of adiposity. Obesity, generally accepted as an increase of BMI beyond 30

Mr Retory and Drs Petitjean and Bonay are affiliated with the Université de Versailles Saint-Quentin en Yvelines, UFR des Sciences de la Santé, Montigny-le-Bretonneux, France, U1179 Inserm, Laboratoire de Physiologie TITAN, Montigny-le-Bretonneux, France, and Service de Physiologie-Explorations Fonctionnelles, Hôpital Ambroise Paré, Assistance Publique-Hôpitaux de Paris, Groupe Hospitalier Paris Ile-de-France Ouest, Boulogne-Billancourt, France. Dr de Picciotto and Ms Niedzialkowski are affiliated with the Service de Physiologie-Explorations Fonctionnelles, Hôpital Ambroise Paré, Assistance Publique-Hôpitaux de Paris, Groupe Hospitalier Paris Ile-de-France Ouest, Boulogne-Billancourt, France. $\mathrm{kg} / \mathrm{m}^{2}$, is generally associated with a higher risk of health disabilities. Among disorders associated with obesity, impairments of lung function are well described at rest and during exercise. ${ }^{1-8}$ Even if obese subjects usually describe dyspnea when performing exercise, physical activity is recognized as an effective tool to limit comorbidities associated with obesity. ${ }^{9}$ Walking is currently recommended

\footnotetext{
This work was supported by funding from the Fonds de Dotation de Recherche en Santé Respiratoire and LVL Medical. The authors have disclosed no conflicts of interest.

Drs Bonay and Petitjean contributed equally to this work.

Correspondence: Yann Retory MSc, Service de Physiologie-Explorations Fonctionnelles, Hôpital Ambroise Paré AP-HP, 9, Avenue Charles de Gaulle, 92100 Boulogne Cedex, France. E-mail: yann.retory@aphp.fr.
}

DOI: $10.4187 /$ respcare. 04426 


\section{BMI-Dependent Ventilatory Parameters From RIP During 6MWT}

in the obese population as well as in the general population because it can provide a safe and effective lifestyle strategy to reduce abdominal obesity and metabolic marker abnormalities. ${ }^{10-14}$ In this context, developing a routine test to explore the impact of obesity-induced impairments of lung function on the ability to walk is essential.

The 6-min walk test (6MWT) used all over the world is a good candidate for evaluating submaximal exercise capacity, but the reference design is not able to give any data on respiratory patterns or limitations. ${ }^{15}$ Respiratory parameters can be measured by validated methods, such as by a pneumotachometer or metabolic device, but these methods require a mouthpiece or a face mask known to introduce biases on respiratory patterns. ${ }^{16,17}$ Respiratory inductive plethysmography (RIP) has been developed as an alternative technique to obtain ventilatory parameters avoiding these biases. Although this method has been validated by numerous studies, ${ }^{18-20}$ this is not the case when considering the obese population; Hollier et $\mathrm{al}^{21}$ reported some limitations, referring to an increased asynchrony and a propensity for generating artifacts in this population.

In this study, we propose an adapted method for using RIP to assess ventilation from subjects with low and high BMIs. The aim of the study was to determine whether the proposed RIP method during a 6MWT is able to describe ventilatory adaptations depending on BMI.

\section{Methods}

\section{Subjects}

The study was performed from January 2014 to June 2015 in the Service de Physiologie-Explorations Fonctionnelles, Hôpital Ambroise Paré AP-HP, Boulogne-Billancourt, France. Twenty-five healthy volunteers (6 men and 19 women) participated in this study and were divided into 2 groups depending on their BMI (Table 1). They provided their informed written consent, and the study was conducted in accordance with the principles of the Declaration of Helsinki. Approval for the study was obtained from the institutional review board of the French Learned Society for Respiratory Medicine "Société de Pneumologie de Langue Française" (2015-23).

\section{Recordings}

A polygraph (NOX T3 sleep monitor, NoxMedical, Reykjavík, Iceland) usually used for sleep disorder diagnoses $^{22}$ was used for several measurements. Subjects were equipped with a small nasal cannula and a thoracic belt connected to the polygraph.

\section{QUICK LOOK}

\section{Current knowledge}

The 6-min walk test in its classical design gives useful information on functional capacity. However, ventilatory adaptations to peripheral oxygen demand increase during walking are not evaluated by this test.

\section{What this paper contributes to our knowledge}

This study reveals that the respiratory inductive plethysmography signal after calibration and filtering procedures can be used for monitoring ventilatory adaptations to exercise during a 6-min walk test without any biases. It allows the observation of different ventilatory behaviors, depending on body mass indices, which are compatible with what is known about ventilatory profiles and body mass index.

\section{MWT}

The 6MWT was performed in a 30-m route in a corridor according to recommendations from the American Thoracic Society. ${ }^{15}$ Average speed by minute was calculated from the walked distance determined by markers and walking time with a stopwatch. Data for activity were collected by using the 3-dimensional accelerometer included in the NOX T3 polygraph at a sampling frequency of $10 \mathrm{~Hz}$ and was used to synchronize signals by discriminating rest from walking.

\section{Ventilatory Parameters}

Nasal pressure and RIP signals were recorded with the polygraph NOX T3, allowing measurements of nasal pres-

Table 1. Anthropometric and Spirometric Data

\begin{tabular}{lccc}
\hline \hline \multicolumn{1}{c}{ Characteristics } & $\begin{array}{c}\text { BMI }>30 \mathrm{~kg} / \mathrm{m}^{2} \\
(n=15)\end{array}$ & $\begin{array}{c}\mathrm{BMI}<25 \mathrm{~kg} / \mathrm{m}^{2} \\
(n=10)\end{array}$ & $P$ \\
\hline Age, mean $\pm \mathrm{SD}$ y & $42.0 \pm 11.9$ & $35.4 \pm 13.8$ & .12 \\
Height, mean $\pm \mathrm{SD} \mathrm{cm}$ & $165.4 \pm 9.9$ & $168.5 \pm 10.0$ & .24 \\
Male/female sex, $n$ & $4 / 11$ & $2 / 8$ & $>.99^{*}$ \\
$\mathrm{BMI}_{\text {m }}$ mean $\pm \mathrm{SD} \mathrm{kg} / \mathrm{m}^{2}$ & $43.5 \pm 5.2$ & $22.8 \pm 1.4$ & $<.001$ \\
$\mathrm{FEV}_{1}$ mean $\pm \mathrm{SD} \mathrm{L}$ & $3.0 \pm 0.5$ & $3.5 \pm 1.0$ & .16 \\
FVC, mean $\pm \mathrm{SD} \mathrm{L}$ & $3.8 \pm 0.6$ & $4.1 \pm 0.9$ & .56 \\
FRC, mean $\pm \mathrm{SD} \mathrm{L}$ & $1.9 \pm 0.3$ & $3.2 \pm 0.8$ & $<.001$
\end{tabular}

$P$ values are for comparison between body mass index $<25 \mathrm{~kg} / \mathrm{m}^{2}$ and body mass index $>30 \mathrm{~kg} / \mathrm{m}^{2}$.

$* P$ value from Fisher exact test.

$\mathrm{BMI}=$ body mass index

$\mathrm{FRC}=$ functional residual capacity 


\section{BMI-Dependent Ventilatory Parameters From RIP During 6MWT}

sure at a sampling frequency of $200 \mathrm{~Hz}$, whereas thoracic RIP signal was recorded at a sampling frequency of $20 \mathrm{~Hz}$. A pulmonary function test machine (Jaeger, Carefusion, Voisins-le-Bretonneux, France) measured $\mathrm{FEV}_{1}$ by integration of respiratory flow at the mouth measured with a calibrated pneumotachometer, whereas functional residual capacity was determined by helium dilution. ${ }^{23}$ Index for dyspnea and lower limb fatigue were assessed by mean of a modified Borg scale in centimeters with a precision of $\pm 1 \mathrm{~cm}$ before and after walking. ${ }^{24}$

\section{Calibration}

Before and after recordings of ventilation, calibration of RIP was carried out by simultaneously measuring volume change by a pneumotachometer and thoracic perimeter change by RIP while the subject was kept standing. Once the calibration maneuvers were initiated, the subjects were not allowed to change their standing posture and to reach the respiratory inductive plethysmograph with their hands. The relationship between perimeter changes measured by RIP and volume measured by the pneumotachometer was determined by a linear regression model. Slopes of these relationships were calculated offline to predict volume changes from perimeter changes between calibration maneuvers.

\section{Protocol}

Measurements were taken in a quiet, warm laboratory room. Determining the absence of obstructive or restrictive disorder by measuring $\mathrm{FEV}_{1}, \mathrm{FVC}$, and functional residual capacity and calculating the $\mathrm{FEV}_{1} / \mathrm{FVC}$ ratio and total lung capacity was the preliminary phase of the protocol. Calibration maneuvers were performed before and after the 6MWT, and 1 min of standing at rest was inserted prior to the $6 \mathrm{MWT}$.

\section{Data Processing}

Data Collection. Data from RIP (nasal pressure, thoracic signal, and actimetry) were analyzed offline by extracting them in .edf format from the polygraph with the dedicated software NOXturnal 3.2 (Nox Medical, Reykjavík, Iceland). Data were then converted into ASCII format by EDFbrowser 1.52 (GNU general public license) in order to be imported into Matlab 2014b (The MathWorks, Natick, Massachusetts) for offline analysis.

Artifact Management. Since motion artifacts can easily contaminate the RIP signal during walking, we used a custom-made algorithm with Matlab software designed in the time domain to remove them (unpublished data). Briefly, artifact removal by this algorithm consists of using nasal pressure signal as a time reference for identification of respiratory cycles on the thoracic signal. This temporal reference allows exclusion of artifacts by keeping only maximum and minimum values localized on ranges corresponding to respiratory cycles on the nasal signal. After artifact removal, ventilatory parameters (tidal volume $\left[\mathrm{V}_{\mathrm{T}}\right]$, inspiratory time $\left[\mathrm{T}_{\mathrm{I}}\right]$, expiratory time $\left[\mathrm{T}_{\mathrm{E}}\right]$, breathing frequency [f], $\mathrm{T}_{\mathrm{I}} / \mathrm{T}_{\text {tot }}$ ratio, and $\mathrm{V}_{\mathrm{T}} / \mathrm{T}_{\mathrm{I}}$ ratio) were calculated.

\section{Statistics}

Statistical analyses were performed by using GraphPad Prism 5.01 for Windows (GraphPad Software, San Diego California). Normality of data were first tested by using a D'Agostino and Pearson omnibus normality test. ${ }^{25}$ Because data were not normally distributed most of the time, correlations were evaluated by Spearman coefficient calculation. Comparisons between groups were evaluated using the Mann-Whitney test. Comparison of sex ratio was made by using a Fisher exact test.

Statistics during the 6MWT were performed with a 2-way ANOVA and the Sidak multiple-comparison test. Effects evaluated were BMI and time during the 6MWT. It is noteworthy that for evaluating these effects, the rest period $(\mathrm{t}=0 \mathrm{~min})$ was excluded. Two-way ANOVA with the Sidak multiple-comparison test was also performed to evaluate the effect of activity (between rest and the first $1 \mathrm{~min}$ ) on $\mathrm{V}_{\mathrm{T}}, \mathrm{f}, \mathrm{T}_{\mathrm{I}}$, and $\mathrm{T}_{\mathrm{E}}$. Size effects were estimated with the Cohen equation, where the first term was $\left(\mathrm{M}_{\mathrm{BMI}}>30-\right.$ $\left.\mathrm{M}_{\mathrm{BMI}<25}\right) / \sigma$ pooled, with $\mathrm{M}_{\mathrm{BMI}>30}$ the mean of the highBMI group, $\mathrm{M}_{\mathrm{BMI}<25}$ the mean of the low-BMI group, and $\sigma$ pooled the average population SD. ${ }^{26}$ Size of exercise effects was calculated with the same equation with the first term as $\left(\mathrm{M}_{\mathrm{T} 6}-\mathrm{M}_{\mathrm{T} 0}\right) / \sigma$ pooled, with $\mathrm{M}_{\mathrm{T} 6}$ the mean of the parameter at the last minute of the $6 \mathrm{MWT}$ and $\mathrm{M}_{\mathrm{T} 0}$ the mean of the parameters at rest. Sizes of the time effect during the 6MWT were calculated with $\left(\mathrm{M}_{\mathrm{Ti}}-\mathrm{M}_{\mathrm{Tj}}\right) / \sigma$ pooled with $\mathrm{i}$ and $\mathrm{j}$ in a range from 1 to 6 . Every pairing of $\mathrm{i}, \mathrm{j}$ possible was assessed, and results were given by means and SD values of all calculations. The strength of the size effect could be interpreted according to the Cohen guidelines ( $\leq 0.4$, small; 0.41-0.7, moderate; $>0.7$, strong).

\section{Results}

As shown in Table 1, there was no significant difference between the group with higher BMIs and the group with lower BMIs for age and height. BMI comparison established a highly significant reduction of functional residual capacity from groups with higher BMIs in comparison with groups with low BMIs $(P<.001$; effect size $=-1.64$ [strong]).

Six-min walk distance in the group with higher BMIs was significantly lower compared with the lower-BMI 


\section{BMI-Dependent Ventilatory Parameters From RIP During 6MWT}

group $(P=.001$; effect size $=-1.22$ [strong] $)($ Table 2$)$, which is in accordance with the effect of BMI from 2-way ANOVA $(P<.001$; effect size $=-1.21$ [strong] $)$ considering walking speed (Table 3). Multiple comparisons show significant differences for walking speed between the higher-BMI group and the lower-BMI group for each minute of the 6MWT $(P=.004, .003, .003, .003, .003$, .005 ; effect size $=-1.23,-1.18,-1.23,-1.23,-1.27$, and -1.15 [all strong] from the first to the last minute) (Fig. 1). Results from the subjective data showed a significant increase of dyspnea and fatigue $(P=.001$; effect size $=1.23$ [strong] and $P=.049$; effect size $=0.87$ [strong]), respectively) for the higher-BMI group in comparison with lower-BMI subjects (Table 2).

From a methodological point of view, 2-way ANOVA showed a BMI effect $(P<.001$; effect size $=1.07$ [strong] $)$, considering the number of artifacts removed by our custom-made algorithm (Table 3 ). In addition, we found a significant correlation between the number of artifacts

Table 2. Data From Walking Test

\begin{tabular}{lccr}
\hline \hline \multicolumn{1}{c}{ Parameter } & $\begin{array}{c}\text { BMI }>30 \mathrm{~kg} / \mathrm{m}^{2} \\
(n=15)\end{array}$ & $\begin{array}{c}\text { BMI }<25 \mathrm{~kg} / \mathrm{m}^{2} \\
(n=10)\end{array}$ & $P$ \\
\hline $\begin{array}{l}\text { Distance, } \mathrm{m} \\
\text { Dyspnea index: Borg } \\
(\mathrm{t} 6-\mathrm{t} 0)\end{array}$ & $\begin{array}{c}486.9 \pm 61.2 \\
\text { Fatigue lower limbs: }\end{array}$ & $583.9 \pm 74.4$ & .001 \\
$\quad$ Borg (t6 $-\mathrm{t} 0)$ & $3.0 \pm 2.5$ & $1.1 \pm 0.8$ & $<.001$ \\
& & $1.1 \pm 1.4$ & .049 \\
\end{tabular}

Data are represented as mean \pm SD. $P$ values are for comparison between BMI $<25 \mathrm{~kg} / \mathrm{m}^{2}$ and BMI $>30 \mathrm{~kg} / \mathrm{m}^{2}$

$\mathrm{BMI}=$ body mass index

$\mathrm{t} 6-\mathrm{t} 0=$ difference between the Borg index at the end of the 6-Min Walk Test and the Borg index at the start.

Table 3. Time and Body Mass Index Effects of Recorded Parameters During the 6-Min Walk Test

\begin{tabular}{|c|c|c|c|c|c|c|}
\hline \multirow{2}{*}{ Parameters } & \multicolumn{2}{|c|}{ Time Effect } & \multicolumn{2}{|c|}{ BMI Effect } & \multicolumn{2}{|c|}{$\begin{array}{c}\text { Interaction Between BMI and } \\
\text { Time }\end{array}$} \\
\hline & $\%$ of Variation & $P$ & $\%$ of Variation & $P$ & $\%$ of Variation & $P$ \\
\hline Speed & 0.20 & $>.99$ & 35.24 & $<.001$ & $<0.001$ & $>.99$ \\
\hline No. of artifacts & 0.14 & $>.99$ & 41.49 & $<.001$ & 0.27 & .99 \\
\hline $\mathrm{V}_{\mathrm{T}}$ & 4.12 & $<.001$ & 10.14 & $<.001$ & 0.20 & .10 \\
\hline $\mathrm{f}$ & 4.45 & .22 & 5.77 & .003 & 3.55 & .34 \\
\hline $\mathrm{T}_{\mathrm{I}}$ & 0.92 & $<.001$ & 0.85 & $<.001$ & 0.25 & .07 \\
\hline $\mathrm{T}_{\mathrm{E}}$ & 0.88 & $<.001$ & 2.25 & $<.001$ & 0.25 & .07 \\
\hline $\mathrm{T}_{\mathrm{I}} / \mathrm{T}_{\text {tot }}$ & 0.13 & .39 & 0.51 & $<.001$ & 0.14 & .38 \\
\hline $\mathrm{V}_{\mathrm{T}} / \mathrm{T}_{\mathrm{I}}$ & 3.57 & $<.001$ & 14.98 & $<.001$ & 0.10 & .46 \\
\hline $\begin{array}{l}\text { The rest period was } \\
\mathrm{BMI}=\text { body mass in } \\
\mathrm{V}_{\mathrm{T}}=\text { tidal volume } \\
\mathrm{f}=\text { breathing frequen } \\
\mathrm{T}_{\mathrm{I}}=\text { inspiratory time } \\
\mathrm{T}_{\mathrm{E}}=\text { expiratory time } \\
\mathrm{T}_{\mathrm{I}} / \mathrm{T}_{\text {tot }}=\text { ratio of insp } \\
\mathrm{V}_{\mathrm{T}} / \mathrm{T}_{\mathrm{I}}=\text { ratio of tidal }\end{array}$ & $\begin{array}{l}\mathrm{T}_{\text {tot }} \text { (inspiratory time } \\
\text { piratory time }\end{array}$ & percentag & ation and $P$ value. & & & \\
\hline
\end{tabular}

removed and BMI individual values $(\mathrm{r}=0.66 P<.001)$ (Fig. 3).

Two-way ANOVA revealed effects of exercise for $\mathrm{V}_{\mathrm{T}}$, f, $\mathrm{T}_{\mathrm{I}}$, and $\mathrm{T}_{\mathrm{E}}(P<.001$ for each of them; effect size $=1.18$, $1.54,-0.7$ and -0.9 , respectively [all strong]). The walking effect explained $10.8 \%$ of variation of $\mathrm{V}_{\mathrm{T}}, 45.4 \%$ of

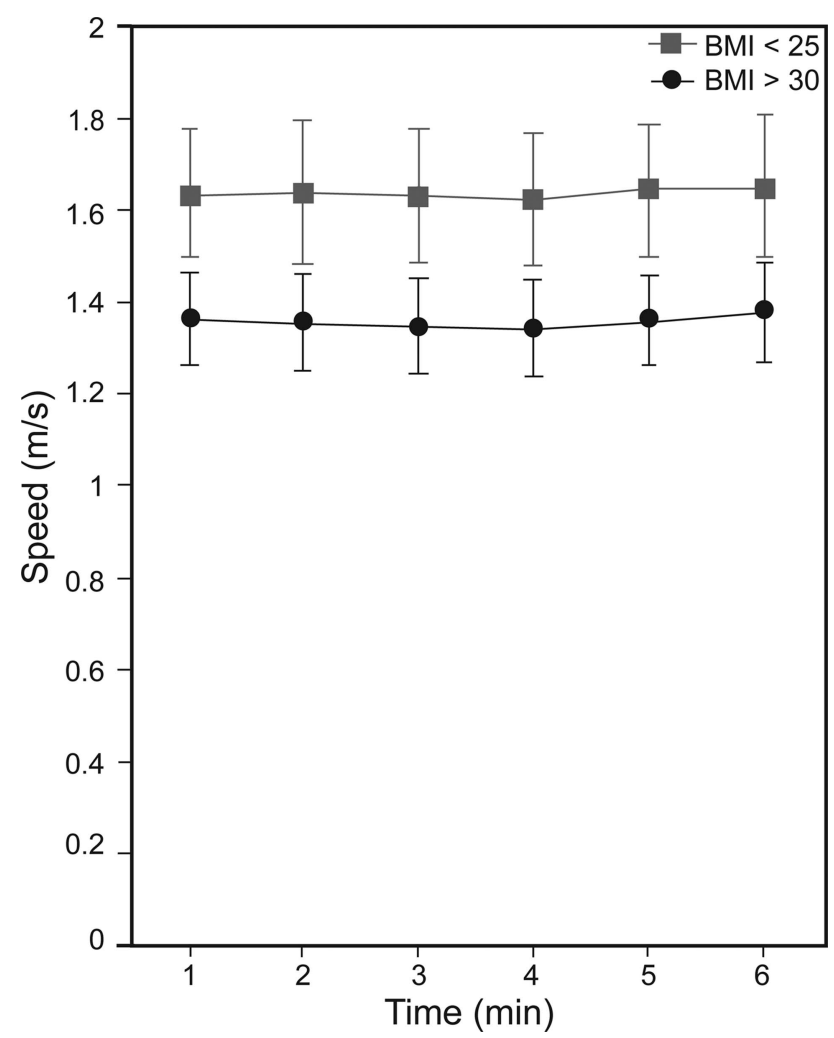

Fig. 1. Average speed during the 6 -min walk test. $P<.01$ between groups for all points. Data are shown as mean and $95 \% \mathrm{Cl}$. 

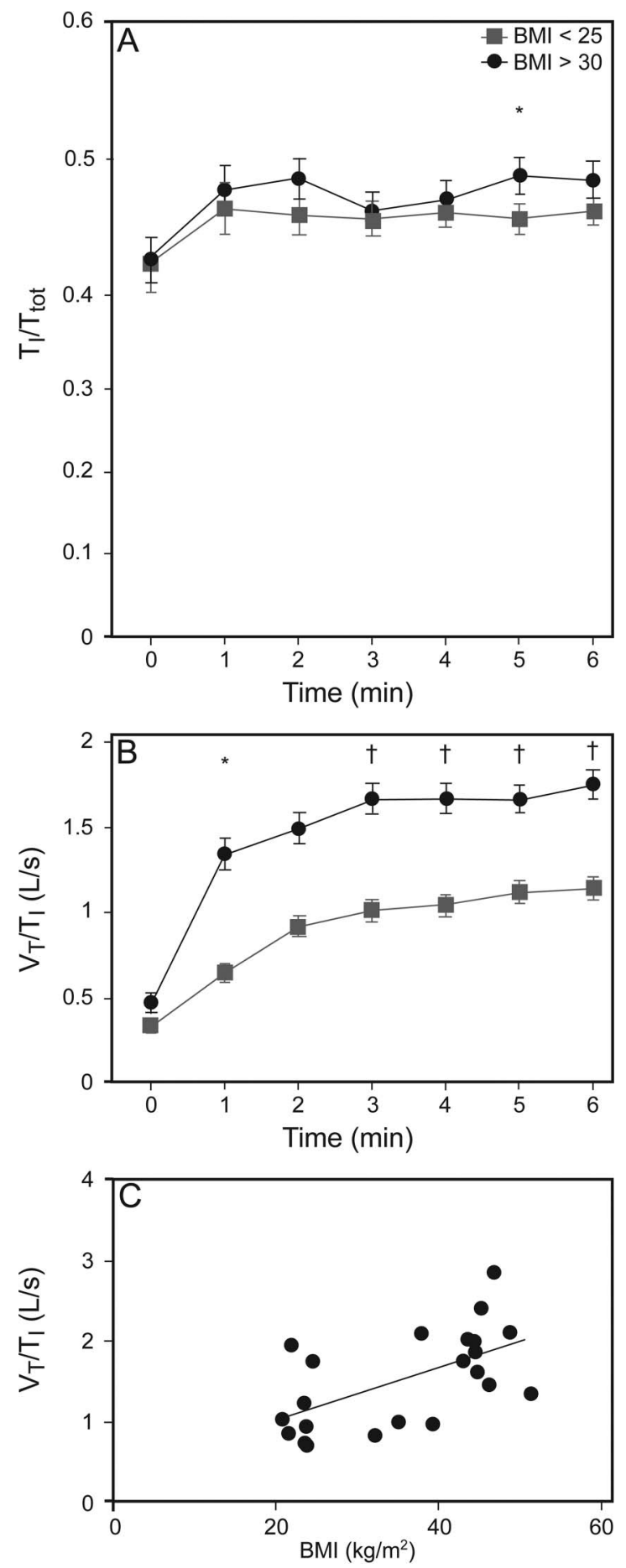

Fig. 2. A: Comparison between groups relying on body mass index (BMI) of inspiratory time/total time $\left(T_{1} / T_{\text {tot }}\right)$ ratio during the 6 -min walk test. B: Comparison between groups relying on body mass index of tidal volume/inspiratory time $\left(\mathrm{V}_{\mathrm{T}} / \mathrm{T}_{1}\right)$ ratio during the 6-min walk test. C: Relationship between tidal volume/inspiratory time ratio at the last minute of the 6 -min walk test and body mass index. Data are represented as mean and $95 \% \mathrm{Cl}$. ${ }^{*} P=.008$; $+P<.001$
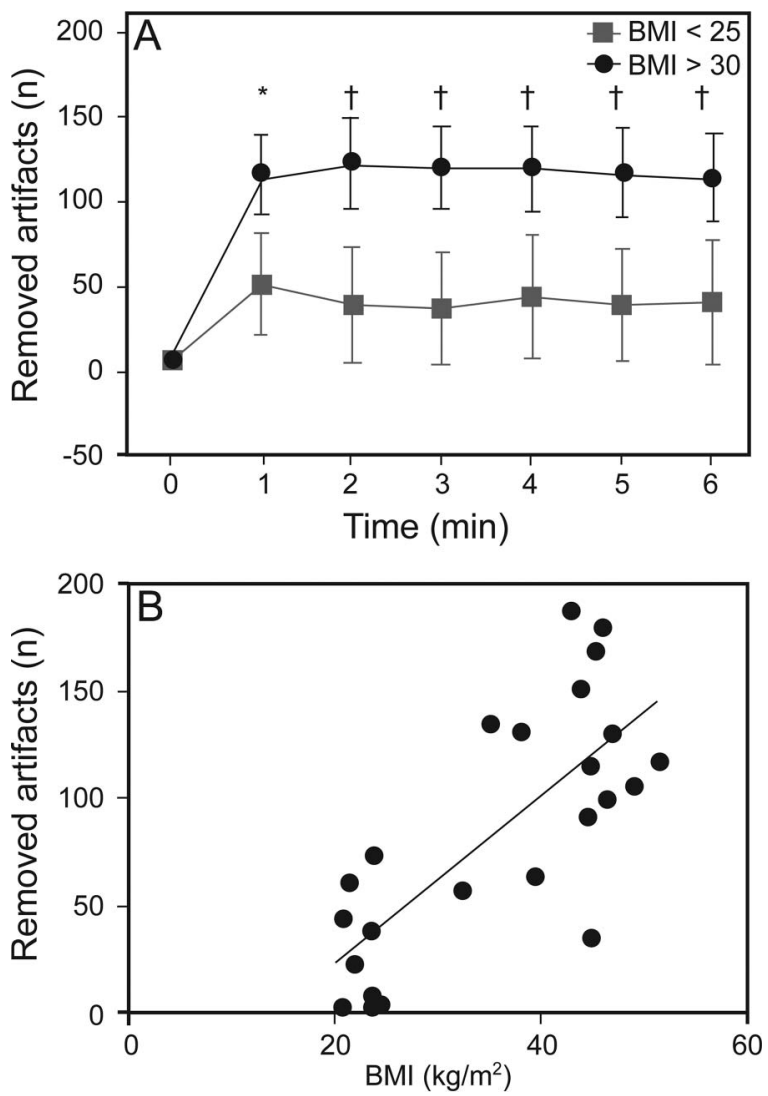

Fig. 3. A: Comparison between groups relying on body mass index (BMI) for number of removed artifacts by custom-made algorithm during the 6 -min walk test. ${ }^{*} P=.005 ;+P<.001$. Data are represented as mean and $95 \% \mathrm{Cl}$. B: Relationship between the mean number of removed artifacts during the 6 -min walk test and body mass index.

variation of $\mathrm{f}, 5.6 \%$ of variation of $\mathrm{T}_{\mathrm{I}}$, and $11.1 \%$ of variation of $\mathrm{T}_{\mathrm{E}}$. The effect of BMI explained $7 \%$ of variation of $\mathrm{V}_{\mathrm{T}}$ and did not explain variation of $\mathrm{f}, \mathrm{T}_{\mathrm{I}}$, and $\mathrm{T}_{\mathrm{E}}$.

During the 6MWT, 2-way ANOVA revealed time effects $(P<.001)$ for $\mathrm{V}_{\mathrm{T}}, \mathrm{T}_{\mathrm{I}}$, and $\mathrm{T}_{\mathrm{E}}$ (effect size $=0.2 \pm$ $0.22,-0.13 \pm 0.09$, and $-0.13 \pm 0.08$, respectively [all small]), whereas a BMI effect was found for $\mathrm{V}_{\mathrm{T}}(P<.001$; effect size $=0.60$ [moderate $])$, $\mathrm{f}(P=.003$; effect size $=0.36[$ small] $), \mathrm{T}_{\mathrm{I}}(P<.001 ;$ effect size $=-0.16$ [small] $)$, and $\mathrm{T}_{\mathrm{E}}(P<.001$; effect size $=-0.25$ [small] $)$ (Table 3). Multiple comparisons showed highly significant $(P<.001 ;$ effect size $=0.83,0.62,0.64,0.68,0.56$, and 0.66 [all strong] from the first to the last minute) minuteby-minute rise of $\mathrm{V}_{\mathrm{T}}$ from higher-BMI subjects in comparison with lower-BMI subjects at each minute of the 6MWT (Fig. 4). Minute-by-minute comparisons of $\mathrm{T}_{\mathrm{I}}$ between the higher-BMI group and lower-BMI group showed at the third and fourth minute significant diminution of $\mathrm{T}_{\mathrm{I}}$ from the higher BMI value $(P<.001$; effect size $=-0.40$ (small) and $P=.009$; effect size $=-0.28$ (small), respectively). The same comparison for $\mathrm{T}_{\mathrm{E}}$ revealed a sig- 

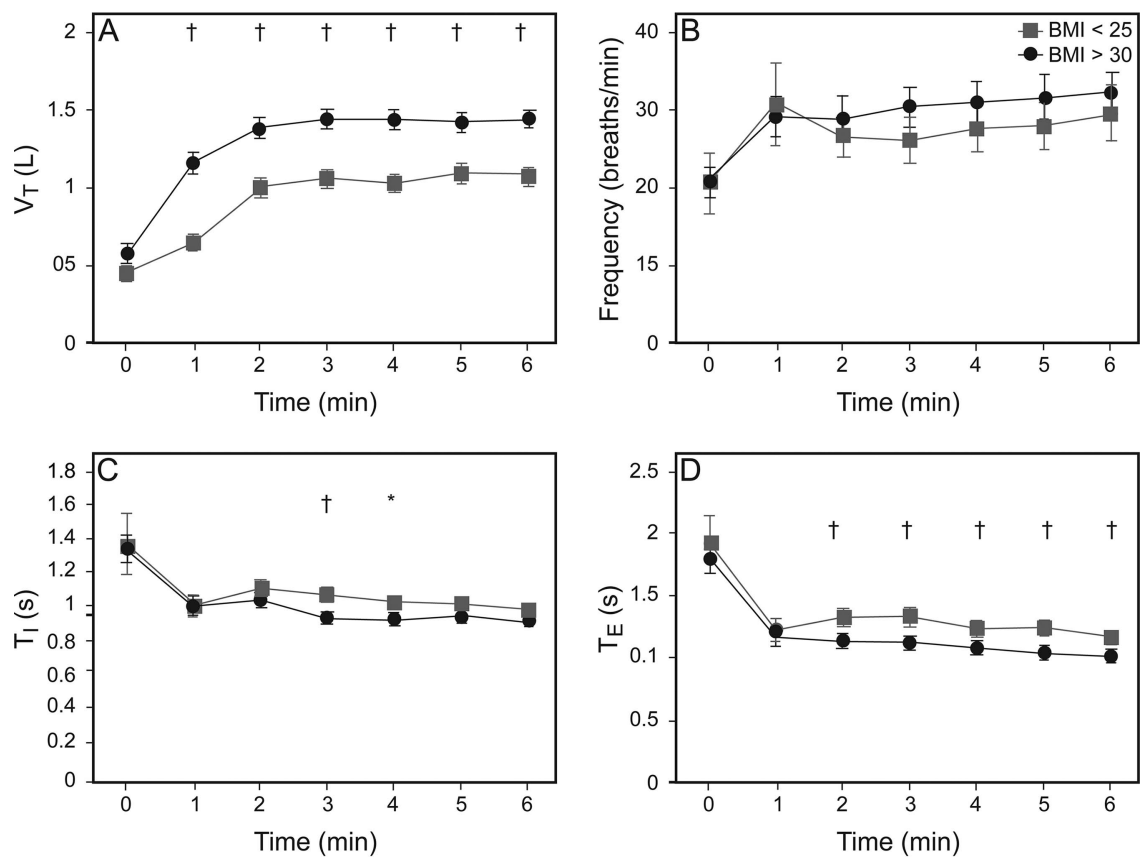

Fig. 4. Comparison between groups relying on body mass index $(\mathrm{BMI})$ during the 6-min walk test. $\mathrm{A}$ : Tidal volume $\left(\mathrm{V}_{\mathrm{T}}\right)$. $\mathrm{B}$ : breathing frequency. $\mathrm{C}$ : inspiratory time $\left(\mathrm{T}_{\mathrm{H}}\right)$. $\mathrm{D}$ : expiratory time $\left(\mathrm{T}_{\mathrm{E}}\right)$. ${ }^{*} P=.009 ; \dagger P<.001$. Data are represented as mean and $95 \% \mathrm{Cl}$.

nificant decrease for subjects with higher BMIs from the second minute up to the last one $(P<.001$; effect size $=-0.38$, $-0.41,-0.31,-0.43$, and -0.34 [almost all small] from the second to the last minute).

Two-way ANOVA revealed time effects for $\mathrm{V}_{\mathrm{T}} / \mathrm{T}_{\mathrm{I}}$ ratio $(P<.001)$ and showed BMI effects for $\mathrm{T}_{\mathrm{I}} / \mathrm{T}_{\text {tot }}$ ratio and $\mathrm{V}_{\mathrm{T}} / \mathrm{T}_{\mathrm{I}}$ ratio $(P<.001$; effect size $=0.14$ [small] and 0.72 [moderate], respectively) during the 6MWT (Table 3). Multiple comparisons show significant minute-by-minute rise of $\mathrm{T}_{\mathrm{I}} / \mathrm{T}_{\text {tot }}$ ratio from subjects with higher BMIs at the fifth minute of the 6MWT $(P=.008$; effect size $=0.28$ [small] $)$. $\mathrm{V}_{\mathrm{T}} / \mathrm{T}_{\mathrm{I}}$ ratio values from higher-BMI subjects were significantly higher $(P<.001$; effect size $=0.90,0.80,0.85$, $0.81,0.73$, and 0.76 [all strong] from the first to the last minute) than those from lower-BMI subjects, from the onset of the 6MWT to its end (Fig. 2). Moreover, significant correlation $(\mathrm{r}=0.61, P=.002)$ was found when considering the relationship between BMI individual values and corresponding $\mathrm{V}_{\mathrm{T}} / \mathrm{T}_{\mathrm{I}}$ ratio values (Fig. 2), whereas there was no correlation between $\mathrm{V}_{\mathrm{T}} / \mathrm{T}_{\mathrm{I}}$ and speed or 6-min walk distance.

\section{Discussion}

\section{Use of RIP in Populations With High BMI}

The use of our custom-made algorithm (unpublished data) for artifact removal appears to be useful when considering the relationship between the number of artifacts removed by the algorithm and BMI (Fig. 3). This is compatible with the relationship described by Hollier et $\mathrm{al}^{21}$ of SD from $V_{T}$ error with waist circumference. This could be explained by a strong link between artifact genesis and overriding fat tissue, which can increase the probability of contaminating the signal when obese subjects are walking. Thus, our algorithm seems to fulfill the need for filtering the RIP signal of people with high BMIs during walking and increases the accuracy of ventilatory parameter measurements.

To our knowledge, there are few data regarding the use of RIP in obese subjects. Hollier et $\mathrm{al}^{21}$ studied the validity of RIP in subjects with obesity hypoventilation syndrome but without any filtering method. This study raises some limitations to the use of RIP for obese people. First, they find good agreement for $\mathrm{f}$ in controls but not for OHS, suggesting the inefficiency for detecting onset and end of respiratory cycles when a high BMI is involved. This is compatible with a treatment of RIP without artifact removal, unlike in this study. Indeed, in our study, the use of nasal pressure signal to determine f seems much better than RIP alone. Previous authors also indicated that RIP belt slippage can easily invalidate assumptions made in the calibration phase. In our study, we chose to limit this issue by flanking measurement time by 2 calibration phases to minimize the possible effect of belt displacements and/or drift of calibration. Furthermore, a high level of respiratory load characteristic of obesity is compatible with a high level of asynchrony frequently occurring and leading 


\section{BMI-Dependent Ventilatory Parameters From RIP During 6MWT}

to inaccuracy when a linear model is used. To avoid this phenomenon, and because nonlinear calibration is not commercially available, we decided to exclusively consider the thoracic belt, ignoring abdominal motions and thoracoabdominal asynchrony issues. Hollier et $\mathrm{al}^{21}$ also noted that deformity of adipose tissue of the belly could attenuate movement detection and lead to an underestimation of calculated $\mathrm{V}_{\mathrm{T}}$. Following this, our significant difference between groups would have been higher if tidal volumes were truly underestimated for the higher-BMI group. However, by applying our method, the level of $\mathrm{V}_{\mathrm{T}}$ for higherBMI subjects at the end of the 6MWT was very close to the range described previously in obese subjects by $\mathrm{Di}$ Thommazo-Luporini et $\mathrm{al}^{27}(1.4 \pm 0.2 \mathrm{~L}$ with $\mathrm{FVC}=3.4 \pm 0.6 \mathrm{~L}$ vs $1.4 \pm 0.6 \mathrm{~L}$ with $\mathrm{FVC}=3.8 \pm 0.6 \mathrm{~L}$ in our study). In the same view, exercise-induced evolution of ventilatory parameters calculated with this method are in accordance with well-known increased respiratory rate and tidal volume during exercise. ${ }^{28}$ This method seems sensitive enough to allow the observation of a ventilation rise during walking, which can be appreciated by time effects observed in this study.

\section{Ventilatory and Locomotor Adaptation of High-BMI Subjects}

Exercise dyspnea is very common in the obese population. ${ }^{29}$ Results from our study were significant with higher Borg scores of dyspnea at the end of the 6MWT. Despite the fact that the Borg score is a subjective index of dyspnea, it highlights the feeling of discomfort in high-BMI subjects when performing submaximal activities like walking for $6 \mathrm{~min}$ at a natural speed. As more objective indices, ventilatory parameters are shown to be significantly higher in high-BMI subjects $\left(\mathrm{V}_{\mathrm{T}}\right.$ and $\mathrm{f}$ ), demonstrating an increase in minute ventilation. The higher $f$ values in highBMI subjects may be explained by significant reduction of $\mathrm{T}_{\mathrm{I}}$ and a more significant diminution of $\mathrm{T}_{\mathrm{E}}$, leading to a significant reduction of respiratory cycle duration. It is likely that they recruit expiratory muscles to increase minute ventilation around or beyond the $40 \mathrm{~L} / \mathrm{min}$ threshold as reported earlier. ${ }^{30,31}$ In the same view, the transition from rest to activity was affected by BMI, with a steeper increase of $V_{T}$ at the first 2 min of the test. The good correlation between $\mathrm{V}_{\mathrm{T}} / \mathrm{T}_{\mathrm{I}}$ at the end of the $6 \mathrm{MWT}$ and $\mathrm{BMI}$ is in accordance with the increased neural drive in obese subjects reported by Babb. ${ }^{32}$ Nevertheless, the difference between groups for $T_{I} / T_{\text {tot }}$ ratio is less marked and could be mainly explained by the greater shortening of $T_{E}$ than of $T_{I}$ in higher-BMI subjects. These results suggest a stronger stimulation of respiratory centers for people with high BMIs during walking.

\section{Conclusion}

Our study demonstrates that respiratory monitoring during 6MWT is able to detect the repercussions of high BMI values over ventilatory adaptation to submaximal exercise. Our results suggest that 6MWT is sufficiently stressful to point out significantly different breathing and locomotor patterns. The use of RIP during walking could be useful to investigate respiratory consequences of lung disorders among various subjects, including obese people.

\section{REFERENCES}

1. Steele RM, Finucane FM, Griffin SJ, Wareham NJ, Ekelund U. Obesity is associated with altered lung function independently of physical activity and fitness. Obesity 2009;17(3):578-584.

2. Vaughan RW, Cork RC, Hollander D. The effect of massive weight loss on arterial oxygenation and pulmonary function tests. Anesthesiology 1981;54(4):325-328.

3. Li AM, Chan D, Wong E, Yin J, Nelson EAS, Fok TF. The effects of obesity on pulmonary function. Arch Dis Child 2003;88(4):361363.

4. Mahadev S, Salome CM, Berend N, King GG. The effect of low lung volume on airway function in obesity. Respir Physiol Neurobiol 2013;188(2):192-199.

5. Nicolacakis K, Skowronski ME, Coreno AJ, West E, Nader NZ, Smith RL, McFadden ER Jr. Observations on the physiological interactions between obesity and asthma. J Appl Physiol 2008;105(5): 1533-1541.

6. Torchio R, Gobbi A, Gulotta C, Dellacà R, Tinivella M, Hyatt RE, et al. Mechanical effects of obesity on airway responsiveness in otherwise healthy humans. J Appl Physiol 2009;107(2):408-416.

7. Littleton SW. Impact of obesity on respiratory function. Respirology 2012;17(1):43-49.

8. Steier J, Lunt A, Hart N, Polkey MI, Moxham J. Observational study of the effect of obesity on lung volumes. Thorax 2014;69(8):752759 .

9. Holub CK, Elder JP, Arredondo EM, Barquera S, Eisenberg CM, Sánchez Romero LM, et al. Obesity control in Latin American and U.S. Latinos: a systematic review. Am J Prev Med 2013;44(5):529537.

10. Donnelly JE, Jacobsen DJ, Heelan KS, Seip R, Smith S. The effects of 18 months of intermittent vs. continuous exercise on aerobic capacity, body weight and composition, and metabolic fitness in previously sedentary, moderately obese females. Int J Obes Relat Metab Disord 2000;24(5):566-572.

11. Duncan JJ, Gordon NF, Scott CB. Women walking for health and fitness. How much is enough? JAMA 1991;266(23):3295-3299.

12. Williford HN, Scharff-Olson M, Blessing DL. Exercise prescription for women: special considerations. Sports Med 1993;15(5):299-311.

13. Jürimäe $T$, Jürimäe $J$, Pihl E. Circulatory response to single circuit weight and walking training sessions of similar energy cost in middle-aged overweight females. Clin Physiol 2000;20(2):143-149.

14. Hong HR, Jeong JO, Kong JY, Lee SH, Yang SH, Ha CD, Kang HS. Effect of walking exercise on abdominal fat, insulin resistance and serum cytokines in obese women. J Exerc Nutrition Biochem 2014; 18(3):277-285.

15. ATS Committee on Proficiency Standards for Clinical Pulmonary Function Laboratories. ATS statement: guidelines for the six-minute walk test. Am J Respir Crit Care Med 2002;166(1):111-117.

16. Perez W, Tobin MJ. Separation of factors responsible for change in breathing pattern induced by instrumentation. J Appl Physiol 1985; 59(5):1515-1520. 


\section{BMI-Dependent Ventilatory Parameters From RIP During 6MWT}

17. Gilbert R, Auchincloss JH Jr, Brodsky J, Boden W. Changes in tidal volume, frequency, and ventilation induced by their measurement. J Appl Physiol 1972;33(2):252-254.

18. Grossman P, Spoerle M, Wilhelm FH. Reliability of respiratory tidal volume estimation by means of ambulatory inductive plethysmography. Biomed Sci Instrum 2006;42:193-198.

19. Kent L, O’Neill B, Davison G, Nevill A, Elborn JS, Bradley JM. Validity and reliability of cardiorespiratory measurements recorded by the LifeShirt during exercise tests. Respir Physiol Neurobiol 2009; 167(2):162-167.

20. Grossman P, Wilhelm FH, Brutsche M. Accuracy of ventilatory measurement employing ambulatory inductive plethysmography during tasks of everyday life. Biol Psychol 2010;84(1):121-128.

21. Hollier CA, Harmer AR, Maxwell LJ, Menadue C, Willson GN, Black DA, Piper AJ. Validation of respiratory inductive plethysmography (LifeShirt) in obesity hypoventilation syndrome. Respir Physiol Neurobiol 2014;194:15-22.

22. Cairns A, Wickwire E, Schaefer E, Nyanjom D. A pilot validation study for the NOX T3(TM) portable monitor for the detection of OSA. Sleep Breath 2014;18(3):609-614.

23. Cazzola M, Rogliani P, Curradi G, Segreti A, Ciaprini C, Pezzuto G, Saltini C. A pilot comparison of helium dilution and plethysmographic lung volumes to assess the impact of a long-acting bronchodilator on lung hyperinflation in COPD. Pulm Pharmacol Ther 2009; 22(6):522-525.

24. Chetta A, Castagnaro A, Foresi A, Del Donno M, Pisi G, Malorgio R, Olivieri D. Assessment of breathlessness perception by Borg scale in asthmatic patients: reproducibility and applicability to different stimuli. J Asthma 2003;40(3):323-329.

25. D'Agostino RB, Stephens MA. Goodness-of-Fit-Techniques. New York: Marcel Dekker, Inc; 1986;68:367-413.

26. Durlak JA. How to select, calculate, and interpret effect sizes. J Pediatr Psychol 2009;34(9):917-928.

27. Di Thommazo-Luporini L, Jürgensen SP, Castello-Simões V, Catai AM, Arena R, Borghi-Silva A. Metabolic and clinical comparative analysis of treadmill six-minute walking test and cardiopulmonary exercise testing in obese and eutrophic women. Rev Bras Fisioter 2012;16(6):469-478.

28. Innocenti Bruni G, Gigliotti F, Scano G. Obstructive sleep apnea (OSA) does not affect ventilatory and perceptual responses to exercise in morbidly obese subjects. Respir Physiol Neurobiol 2012; 183(3):193-200.

29. Launois C, Barbe C, Bertin E, Nardi J, Perotin JM, Dury S, et al. The modified Medical Research Council scale for the assessment of dyspnea in daily living in obesity: a pilot study. BMC Pulm Med 2012; 12:61-62.

30. Abraham KA, Feingold H, Fuller DD, Jenkins M, Mateika JH, Fregosi RF. Respiratory-related activation of human abdominal muscles during exercise. J Physiol 2002;541(Pt 2):653-663.

31. Campbell EJ, Green JH. The behaviour of the abdominal muscles and the intra-abdominal pressure during quiet breathing and increased pulmonary ventilation; a study in man. J Physiol 1955;127(2):423426.

32. Babb TG. Obesity: challenges to ventilatory control during exercise: a brief review. Respir Physiol Neurobiol 2013;189(2):364-370. 